\title{
Poet, Audience, Time, and Text: Reflections on Medium and Mode in Homer and Virgil
}

\author{
Elizabeth Minchin
}

\section{Introduction: Talking and Listening; Writing and Reading}

When oral theory first was developed and applied from within classical studies in the 1930s attention was focused primarily on the Homeric texts and their so-called formulaic language: scholars considered the nature of the formula and its role and function in oral traditional poetry, always from the poet's perspective. ${ }^{1}$ Over the last 80 years the assumption has been that the mode (oral presentation) and the medium (the spoken word) limit, or otherwise guide, the choices of the poet as he composes his tale in performance-and that this is a satisfactory explanation of a number of remarkable surface features of oral poetry. I wish to modify that view. Taking my lead from Wallace Chafe's accounts of spoken and written language, from cognitive research, and from Deborah Tannen's paper on giving a paper at a scholarly conference, I shall argue that transmission does not exist in a vacuum: the audience's mode of reception (listening/reading) as well as the occasion itself must also be taken into account.

In this paper I shall compare Homer's approach to storytelling as we observe it in the Iliad, a record of an oral song composed or improvised in performance for a listening audience, and Virgil's approach to this same task in the Aeneid. This was a poem composed with the aid of writing, which was presented to a listening audience in the first instance and, subsequently, to an audience of readers. I shall study a selection of compositional strategies as they occur in each epic. As we consider Homer's oral traditional song and Virgil's written poem, I shall suggest that there is no doubt that the medium matters, but that the poet's awareness that he is performing for an audience that listens or for an audience that reads - with special focus on the circumstances in which they listen or read-is a critical factor in determining the way in which he presents his tale and in governing the complexity of its content.

1 The basic texts here are the papers included in Parry (1987), but one might consider also the work of James Notopoulos, esp. Notopoulos (1949 and 1951). 
We all accept that the two modes of communication, speech and writing, have different strengths and different weaknesses; and that they are appropriate for different communicative tasks in different contexts. Each mode exhibits some distinctive linguistic features. In his 1982 English-language study Wallace Chafe identified several features that are more common in informal oral conversation, conducted in real time, than in written composition: these include fragmentation (which we also know as anaphora); parataxis; ${ }^{2}$ first person references; the monitoring of information flow; emphatic particles; fuzziness (vagueness and hedging: expressions such as 'sort of', 'kind of', and 'and so on'); and direct quotation. ${ }^{3}$ Chafe contrasts these features of oral conversation with certain characteristics of written language: nominalization, attributive adjectives, series (that is, lists), sequences of prepositional phrases, complement clauses, relative clauses - all of which, he observes, permit the integration of more material into idea units within a written text. ${ }^{4}$

Many of the differences between oral and written discourse may be attributed to the interrelationship of the time available to the speakers, or the writers, as they compose and their capacity for processing new material. So that we might better understand the limitations faced by a speaker, by contrast with a writer, I begin with some studies of the capacity of memory. Some decades ago, George Miller estimated that short term memory is able to process between five and nine pieces of information simultaneously. More recently, Nelson Cowan narrowed Miller's estimate to just four. ${ }^{5}$ I shall use the short-hand term 'cognitive ceiling' to encapsulate this limitation. ${ }^{6}$ Since the time-frame available for the production of oral discourse is markedly different from that available for the composition of a written text, the 'cognitive ceiling' is lower for those producing oral discourse and higher for those working in writing. What is crucial to this discussion is that very similar limitations must apply also to the

2 I shall use the phrase 'adding-on' to refer to this practice in oral contexts.

3 See Chafe (1982: $35^{-36}$ ), for an outline of his study. And see $46-48$ for Chafe's discussion of features that signal the speaker's involvement with the audience. Cf. Russo (1999: 157159).

4 Chafe (1982: 48-49). Biber (1988: 106-107) points out, however, that relative clauses, along with causal clauses ('because'), sentence relatives, and conditional subordination, are also a feature of oral discourse. See also Miller and Weinert (1998: 18-23).

5 See Miller (1956); Cowan (2001). Cowan is particularly concerned with focus of attention.

6 See Biber (1988: 163). As Biber points out, spoken genres are produced and comprehended in real time; this real-time limitation sets a relatively low cognitive ceiling. See also Miller and Weinert (1998: 79-80). 
recipients of such texts: those who listen and those who have the leisure to read will likewise operate under different cognitive ceilings. ${ }^{7}$ So, elaborating on a remark by Deborah Tannen, I conclude that talking and listening are in cognitive terms nicely suited to each other, as are writing and reading. ${ }^{8}$ That is, when speakers improvise for a listening audience they operate not only within their own cognitive limits but, quite naturally, within the limits of their listeners as well. On the other hand, a tightly-argued, well-integrated text produced by a writer who has spent long hours on its preparation, is best appreciated by an audience of educated readers who can work though the text at their own pace, lingering where necessary over difficult phrasing and more complex ideas. ${ }^{9}$

To emphasize this point with a counter-example, I suggest we consider for a moment the hybrid situation that we observe at an academic conference or seminar: when a speaker reads to a listening audience a tightly integrated paper, a written text that has been composed and revised over an extended period of time for 'imagined recipients' 10 —and his or her listeners are subsequently obliged to concentrate to the exclusion of all else if they are to follow the argument. ${ }^{11}$

With these principles and these scenarios in mind, I turn to ancient epic and consider the compositional features of, first, Homeric epic and subsequently Virgil's Aeneid from the perspective of both poet and audience.

7 Is an individual's cognitive ceiling in an oral culture higher than it is today in listening audiences (from a literate culture) who are processing oral discourse? For discussion (leading to a general conclusion that orality does not necessarily imply a more capable short term memory), see Neisser (1982: 241-242 and n. 1); Scribner and Cole (1981: chs. 1 and 13).

8 See Tannen (1988: esp. at 37).

9 For useful commentary see Hildyard and Olson (1982: esp. at 31-32). On the critical importance of education as a qualification for processing complex material, see Miller and Weinert (1998: 21).

10 For the concept of the 'imagined recipient', see Erving Goffman's essay 'Footing': Goffman (1981: 138). Here Goffman notes the different relationship of the speaker to his or her audiences and observes that where recipients are on a different footing the speaker may adjust his talk now for one, now for the other.

11 In many cases they fail completely to do so: the argument is too dense. Many speakers, on the other hand, are not unaware of the difficulties that this situation poses- the paper handout or the text of a powerpoint is an attempt to compensate for the fugacity of the spoken word. 


\section{Texts Composed Orally for a Listening Audience: The Homeric Epics}

Several of the 'oral' features of everyday conversation that Chafe has identified are attested in the Homeric texts. Conspicuously present in both the Iliad and the Odyssey (in their narrative passages, that is) is the 'adding-on' habit (which represents the flow of a speaker's consciousness), ${ }^{12}$ emphatic particles (that may indicate the viewpoint or attitude of the speaker, the focus of his or her attention, or the way in which a new piece of information connects with what has gone before), ${ }^{13}$ and direct quotation (which, in its simple directness, uses the actual words of the speaker rather than presenting them indirectly). ${ }^{14}$ These features all reflect, in one way or another, the mental activity of the speaker or, in our case, the singer, and the pragmatic choices he or she makes as he or she tells a story. There are, of course, features of everyday oral conversation that are not present in the Homeric epics: frequent first person references to the storytelling 'I', for example, or Chafe's 'fuzziness', which reflects the hesitancy of the average speaker who is composing in real time.

On the other hand we observe in Homer's texts a number of Chafe's socalled 'written' features, in some cases in abundance: attributive adjectives, ${ }^{15}$ sequences of prepositional phrases, series or lists, complement clauses, ${ }^{16}$ and adverbs of time and place. In Homer, that is, we observe many but not all of the features that Chafe associates with oral conversational discourse and several

12 Noted by Notopoulos (1949). And see Bakker's eloquent defence of the poet's paratactic style: Bakker (1997: 36-44). Bakker (1997: 44-53, esp. at 52) refines this idea on the basis of Chafe's work on intonation units - that is, simple verbal ideas or individual formulas. For typical instances of the 'adding on' strategy in Homer, see Il. 11.211-217 (within narrative) and $16.517-522$ (within character speech). On parataxis more generally, in spontaneous spoken language, see Miller and Weinert (1998: 22).

13 On 'focus constructions' in general, see Miller and Weinert (1998: chap. 5) and, on one particle as it occurs in Homer, see Bakker (1993: 275-311); Bakker (1988).

14 The conversion of direct speech to indirect speech presents small additional challenges to the storyteller-namely the adjustment of pronoun and verb forms. These small changes require both time and an effort of short-term memory. Direct speech also works for the poet as an internal evaluative device, as Aristotle noted at Poetics 146oa5-11. On this see strategy more generally see Labov (1972: ch. 9, esp. 370-373); Gulich and Quasthoff (1986: 222-224).

15 On Homer's use of attributive adjectives, however, see below.

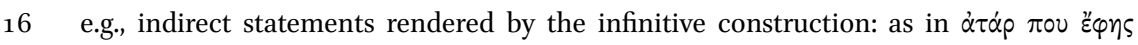

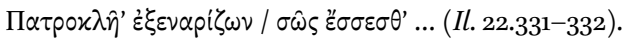


features that he associates with written discourse. To explain this commingling of discourse styles in oral epic we should consider another context in which we find spoken language.

\section{Oral Epic and the Stylization of Ordinary Discourse}

As a kind of afterthought to his discussion of oral conversation, Chafe introduces us to oral language that is used not in the informal everyday context that is the focus of so much of his research but in oral 'texts' that are identified with ritual behaviour. ${ }^{17} \mathrm{He}$ finds that in ritual performance the language used may be less like colloquial everyday language and 'more like written' language. The point he is making here is that social factors like the value and the permanence of a ritual oral text (such as traditional epic song) and the esteem in which it is held may influence the quality of its language; and, of course, repeated opportunities for rehearsal and revision must also play a part. It should not surprise us, therefore, that because of these factors and these opportunities, the language of ritual (and of oral literature) is more formalized and more polished. ${ }^{18}$

When we turn back to Homer to seek further evidence of this 'more like written' language we observe in the careful formality of his presentation at every level (whether the phrase, the type-scene, or the episode) that the singer has indeed achieved the 'literary' qualities of permanence, polish and value. It is an irony (and a potential source of confusion) that Homer's texts might be identified as 'more like written' - not because they were written but because they were formalized. Egbert Bakker, however, dispelled confusion when he proposed the term 'special' to describe aspects of epic presentation such as Homer's use of formulaic language and his adoption of a stylized and standardized type-scene presentation. ${ }^{19}$ The 'stylization of ordinary discourse' (to use Bakker's phrase) that we observe even in these smaller units of song, in for-

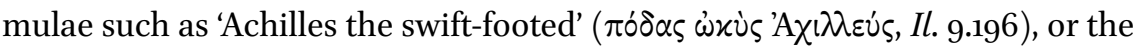

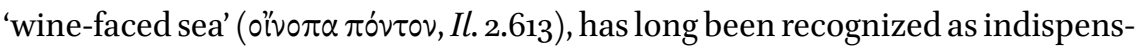
able to the poet/singer in the face of the demands of composition in perfor-

17 Chafe (1982: 49-52, esp. 52), on the ritual language of the Seneca-Iroquois.

18 On the polish that rehearsal and revision can endow, see Edmund de Waal's comment on his uncle's frequently related stories; he notes the 'way that repetition wears things smooth': de Waal (2011: 6).

19 This discussion of formulae as 'poetry in speech' owes much to Bakker (1997, esp. chapter 7 ). 
mance. ${ }^{20}$ I shall suggest, however, that this language, which may have seemed strange to the first-time listener, was also advantageous to him, or to her. ${ }^{21}$

\section{Strategies of Composition: The Oral Poet and His Audience of Listeners}

We must remember that the Iliad itself is a song on a monumental scale; details are narrated in full; action is piled on action. The song moves ever forward. As I noted above, the use of co-ordinating conjunctions to link narrative actions, or direct speech instead of indirect, makes storytelling easier for the singer, since he is not investing effort in the processes of subordination as he sings. The same is true for the listener, for whom that small extra processing task would be an added burden. The 'adding-on' strategy is natural to storytelling in everyday conversation; it is therefore well suited to composing, and processing, the event-sequences of epic song. Likewise, direct speech is easy for the singer to improvise, since, in reporting speech as it was spoken, he can avoid the processes of subordination - and the complex adjustment of personal pronouns - that indirect expression would entail; and it is easier for the listener to follow, for precisely the same reasons. This is not to say, however, that all direct speech is going to be easily comprehensible. We note that in Homer's character-speech there is much scope for argument and deliberation and complexity of thought - just as there is in everyday discourse. $^{22}$

As for features of the singer's 'special language' and their value to the listener, the formulaic phrase (often a noun qualified by an epithet) not only takes an audience member into the epic world, where every artefact is identified as admirable or exquisite, ${ }^{23}$ but — and this is significant for my argument here-it eases the task of listening because it is repeated. The resulting phrase or verse, which takes somewhat longer to enunciate than a noun unadorned, slows

20 See Bakker (1997: 17). Stylization is a practice that we observe also in oral conversational storytelling (e.g., formulaic introductions such as 'Did I ever tell you about ..., 'Stop me if you have heard this before ...').

21 I build on the notion set out in Bakker (1997: 159 ff.), of 'plus-value'. cf. also Foley (1991) on 'traditional referentiality'; Scodel (2002: 11-13).

22 The quarrel between Agamemnon and Achilles in Iliad 1 demonstrates the syntactic variation possible in direct speech. Here we find conditional clauses, indirect statements, purpose clauses, temporal clauses.

23 See esp. Russo (1999: 168-169). 
the presentation of new information and allows listeners an extra moment to absorb it. ${ }^{24}$ I should make it clear at this point that this 'moment' may be measured only in seconds and fractions of a second; but even so brief a period is as welcome to the listener as it is to the singer.

If we now move beyond words and phrases to accounts of events and actions, we observe that the type-scenes that form the foundations of narrative (arming scenes, dressing scenes, food preparation scenes) unfold in sequences of wellrehearsed actions; they too are spelt out in a standardized poetic language with which the audience quickly becomes familiar.

This may be an audience that has gathered to mark a special occasion (a festival or a marriage) with a sustained performance of the Iliad, such as the night-long performances proposed by Oliver Taplin and others. ${ }^{25}$ During such overnight performances a listener's attention may wander; sleep may occasionally overpower one or two; some may be distracted by hunger or thirst. Repetition, therefore, was invaluable as a core principle of oral traditional song. I noted above repetition at the level of the formula and repetition at the level of type-scene. There is also observable repetition at the level of narrative: we find such repetition in, for example, the messages that are passed from one god or one hero to another in this oral tradition. When Zeus sends Dream with a message to Agamemnon, urging him to arm the Achaeans for battle (Il. 2.11-15), Dream repeats that message to Agamemnon (Il. 2.28-33); then Agamemnon repeats the message again $\left(I l .2 .65^{-70}\right)$ as he recounts his experience to the leaders of the Achaeans. At the end of the epic, when Zeus passes a message to Achilles via Thetis, we hear the message that Zeus gives to Thetis (Il. 24.113-116) and we hear Thetis passing on that same message (carefully edited) to Achilles (Il. 24. 134-136). Each cluster of repeated messages heralds a new episode in the narrative. Such repetition is obviously a welcome moment of respite for the singer; and it also has value for the listener. Repetition gives audience members who may occasionally lose concentration one more opportunity to register a new turn of events.

Another distinctive strategy that serves to restrain the onward movement of narration, and which gives the listener time to process the events of the

\footnotetext{
24 Thus capacity in short-term memory is freed to focus on the storyline and to absorb the poet's evaluative cues: Tannen (1982a: 6-8); Tannen (1982b: 8); Minchin (2001: 123-124). See also Haslam (1997: 66) (although Haslam's discussion then proceeds in a different direction from mine).

25 See Taplin (1995:1-45, esp. 25-28). Taplin argues for a performance of the whole song over three nights, with the performances lasting $9 \mathrm{~h} .25 \mathrm{~m} ., 8 \mathrm{~h} .56 \mathrm{~m}$., and $6 \mathrm{~h} .39 \mathrm{~m}$. respectively. For another version of a three-part hypothesis, see Kirk (1985: 45-46).
} 
narrative and their implications, is the extended, so-called 'Homeric', simile. Through the simile the singer is able to dwell for a few moments longer on an action in the narrative proper, and by these means to convey this significance to his audience.

Similes in Homer have been studied from many perspectives. Of particular relevance to this discussion, however, is the way in which visual memory supports both the singer as he composes his similes and the members of the audience as they process them. Homeric similes exist as a collection of images of men and women or creatures in the wild (or, for that matter, the different aspects of weather) doing what they normally do. ${ }^{26}$ For example, the surge of human emotions may well be explained in Homeric storytelling in terms of the typical reactions of wild boar or deer or birds or bees. The singer's use of such familiar images becomes both a strategy for emphasis and a strategy for involvement. The simile offers itself as a model for a particular event-sequence within the narrative; Homer's listeners are encouraged to bring up this similescene before their mind's eye and to complete the comparison as the singer wishes. ${ }^{27}$

As the juice of a small branch of a fig tree when stirred in milk 'fixes' the milk rapidly and causes it to curdle, so the herbs of the healing god Paeeon, once applied, promptly cause Ares' wounds to stop bleeding (Il.5.902-904):

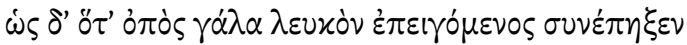

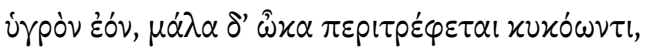

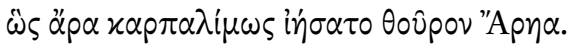

As when the juice of the fig in white milk rapidly fixes that which was fluid before and curdles quickly for one who stirs it; in such speed as this he healed violent Ares.

transl. LATTIMORE

26 That is, animals, mankind, and weather are entities that 'do' things that we understand: see Ready (2012: 74). For categories of themes that provide vehicles for similes, see Redfield (1975: 188-189); on the range of Homeric comparisons, see Ready (2011: 19-25).

27 Minchin (2001: ch. 4). As Jonathan Ready pointed out at the conference, a simile may either precede or follow the event-sequence with which it is compared. Thus it will either prepare the audience for what is to come (e.g. the simile at Il. 22.26-31 prepares us for line 32 , 'so the bronze around his chest gleamed as he ran'); or it explains an event-sequence that has already been narrated (thus the simile at 22.162-164 asks us to linger over and review the desperation of the race around the city of Troy, mentioned at $157-160)$. 
The process of making cheese from fresh milk is age-old, almost timeless, and certainly familiar to Homer's listening audience. The economical description of the process (the fig juice; the fresh milk; the stirring; the curdling), models Paeeon's care of Ares' bleeding wounds, and brings the audience to the point where they can readily envisage the apparent miracle of liquid blood as liquid no more. Thus a selected narrative moment becomes 'recognizable, vivid, and unambiguous' ${ }^{28}$ the experience of listening is enhanced by what we might call the intimacy of recognition; the audience is thereby engaged; and the pleasures of that narrative moment are prolonged.

We should remember, then, that these were performances for everyone. A performance at a religious festival or a wedding would draw a wide crosssection of listeners; some would be better listeners, more experienced and more attentive than others. It was the singer's task to remain attuned to his audience's needs and to ensure that as many as possible of his listeners remained involved until he brought his tale to its close. Therefore, although epic song in an oral tradition moves ever forward, as I noted above, the pace at which it moves, marked by repetitions of all kinds, is deliberately unhurried.

\section{A Text Composed in Writing: Virgil's Aeneid}

\section{Listeners and Readers}

In order to make a more useful comparison between a text composed from within an oral culture and a text composed with the aid of writing, and the reception of each, I turn to Virgil's Aeneid, a creative reworking, in writing, of Homeric material for significant new ends. ${ }^{29}$ As we shall see, the reading audience of a poet who composed in writing worked just as hard as the listening audience of an oral traditional poet; they worked, however, at different tasks.

Holt Parker's spirited defence of the role of the written word in the Roman world and his claim (which I accept) that literature in the Roman empire was meant to be, and was, disseminated in books, does not contradict the view that, for many members of the reading public in Rome, their first acquaintance with a literary work would have been through performance. ${ }^{30}$

28 Minchin (2001: 160).

29 On this see Knauer (1990: 390-412).

$30 \quad$ Parker (2009: 212 and cf. 217). There were indeed opportunities to hear Virgil's Aeneid at readings: see Aelius Donatus, Life of Virgil 26-34, esp. 32 (on Octavia fainting at the 
In the Roman world, the 'first outing' of a work composed in writing would most probably have been an oral performance, a recitatio, at which a poet read a polished draft before a listening audience. ${ }^{31}$ But a recitatio or a performance at a convivium (where a lector read the work of others to a listening audience) did not offer the audience the same experience, or make the same demands, as a night-long performance of oral epic song. Recitationes and performances at convivia were performances of portions of or excerpts from larger works. ${ }^{32}$ They were comparatively brief. ${ }^{33}$ And the audience was quite different. The recitatio, in particular, was an upper-class social ritual. ${ }^{34}$ Audience members were selected precisely because they would be good listeners for a literary work, as Pliny tells us; their command of language and their experience of literary models would have been sophisticated. ${ }^{35}$

Did Virgil have his listening audience in mind, as he adapted the techniques of oral storytelling - techniques that were embedded in the Homeric epics, proven models for epic song? Or was he more interested in refining his composition and enriching it for his readers? ${ }^{36}$ These questions touch on the wider issue of how Virgil, as a poet who composed in writing, approached the act of composition and how he responded to the opportunities, and the challenges, offered by the written mode. As a first step in my discussion of the transmission of Virgilian epic song, I shall look for the surface features of traditional oral epic that I identified in the case of Homer: formulaic language, type-scenes, the

references to Marcellus, Aen. 6.855ff.); Suetonius, Life of Virgil $3^{1}$ (where see also an instance of improvisation on Virgil's part).

31 See Parker (2009: 208): a recitation gave 'only the penultimate draft of a work in progress' the final version being the 'written, public book'. This sequence is paralleled in our own academic world, in which the penultimate version of a journal article or book chapter is the version that has its first outing at a conference.

32 Parker (2009: 208).

33 Pliny the Younger's practice may provide the exception that proves the rule. At Letters 8.21 he refers to a recitation that lasts two days - although, he says, he chose short pieces. Nevertheless, Pliny read whole passages, leaving nothing out ('nihil praetereo'), despite the fact that the practice of reading only selected passages was thought to be more restrained ('modestius') and possibly more considerate ('fortasse reverentius'). Pliny does not seem embarrassed by having commandeered the attention of his friends for such a long period. Virgil (n. 30 above), perhaps with more consideration, read portions only of Aen. 2, 4, and 6 to the imperial family.

34 Parker (2009: 205).

35 At Letters 7.17 Pliny tells us that he does not invite the general public, but a select and limited audience of persons ('certos electosque') whom he admires and trusts.

36 See Goffman (1981: 138), on 'footing'; and see above. 
'adding-on' habit, direct speech, and similes; then I shall discuss the opportunities and challenges that present themselves to the poet as he composes in writing - for an imagined audience.

\section{Strategies of Composition: Virgil and His Audiences of Listeners and Readers}

Although we find some formulaic language in the Aeneid, it is far less intensively used here than in Homeric epics - and it is used to different ends. Walter Moskalew notes, following Milman Parry, that Virgil, in creating noun-epithet phrases and in re-using them, was making 'a deliberate effort to imitate the texture' of traditional epic - conveying the essence rather than creating a facsimile. ${ }^{37}$ Indeed, as Stephen Scully observes, Virgil's epithets are not 'genuinely Homeric'- that is, they do not serve the purpose for which they were originally developed. Taking pius Aeneas as an example, Scully observes that the nounepithet combination does not evoke a 'concrete and easily visualized' image, as do, for example, the formulas that we find in Homer: 'well-founded citadel' (Il.4.33), 'strong-greaved Achaeans' (Il. 1.17), 'ox-eyed Hera' (Il. 4.50); rather, pius Aeneas causes us to reflect on and ponder Aeneas's nature and his heroism. ${ }^{38}$ So even as Virgil's 'formula', on the surface at least, imitates the texture of Homeric song and reminds us of the tradition that Virgil identifies himself with, of course, it also serves a different function, a deeper evaluative function.

As for type-scenes in the Aeneid, there are, I would argue, no thoroughgoing examples of the stylized 'Homeric' kind. Clausen has netted a few 'type-scenes' from the text: two banquet scenes, one sleep scene, three arming scenes and a dressing scene. ${ }^{39}$ Only the two arming scenes of $11.486-491$ and $12.87-95$ (as

37 Moskalew (1982: 99): cf. Parry (1987: 300), who calculated from E. Albrecht's figures that Virgil used a repeated word or phrase every 2oth line - far less than does Homer. Virgil, of course, did not understand the deeper motives for Homer's practice; Virgil imitated what in his view was simply a surface feature of the text. Although Virgil may make very little use of oral traditional formulae, he does make use of repetition. These repetitions of words or phrases are intended for special effects. Thus Tarrant (2012) draws special attention to the poet's repetitions in Aen. 12, using terms such as 'underscores', 'emphasizes', 'vividness', 'solemnity', 'oppressive', 'high drama', 'pathos'. That is, when we identify repetition in a literary text we look for a motive. (For repetition without an obvious motive, see Tarrant [2012: on Aen. 12.224].)

38 On the visual and concrete nature of the Homeric epithet, see Vivante (1982: 174-175); Scully (1990: ch. 5 and 130-136). On the Virgilian epithet, see Scully (2006: 405-406).

See Clausen (2002: 9-13, esp. 12). 
Turnus arms) and the dressing scene (Evander in Aen. 8) even begin to meet the criteria that have been established for a Homeric type-scene; and yet even here we find no characteristically prolonged sequence featuring a standardized sequence of actions, and the words and phrases used to express these actions are not common to each scene. Virgil's banquet scenes certainly allude to their Homeric precedents: the banqueting scene at Aen.1.210-215 offers an echo of an Iliadic scene; the scene at $699-706$ recalls a scene from the Odyssey. ${ }^{40}$ But that is all. Virgil has no urgent need for standardized type-scenes of the Homeric kind; he refers to such scenes to indicate his links with Homer and, in the case of the three scenes I noted above, to mark out those heroes (Evander and Turnus) as Homeric figures. ${ }^{41}$ What we conclude from these observations is that just as Virgil, a poet who composes in writing, has no need for Homeric formulas or type-scenes, neither does his audience.

I turn now to my third category, the 'adding-on' habit, or parataxis. I should note at this point that, just as we occasionally find more complex syntax in the character-speech of the Homeric epics, so in the spoken exchanges of the Aeneid we find subordination and greater complexity. ${ }^{42}$ Nevertheless, throughout the narrative stretches of the poem we observe Virgil's preference for parataxis. ${ }^{43}$ Horsfall suggests that Virgil may have preferred parataxis in narrative as a means for achieving what we could consider one of the principal goals of a poet who writes: he aims for a 'swift smooth movement' in the line. ${ }^{44}$ That is, Virgil uses an 'adding on' strategy for poetic rather than pragmatic ends.

Fourth: the representation of direct speech. Gilbert Highet's painstaking tallies of speakers and speeches reveal that almost half of the Aeneid is devoted to direct speech $\left(46.75 \%\right.$, in fact). ${ }^{45}$ As I observed above, speech is far easier

40 For Iliadic type-scenes that describe the preparation of a meal, see, e.g., Il. 1.458-468; 7.313-322; 9.205-221. For Odyssean type-scenes that describe the hospitality associated with the meal, see, e.g., $\mathrm{Od}$. 4.49-67; 7.167-183.

41 Clausen (2002: 12).

42 A single example will suffice here: see Aen. 7.107-147, a passage that includes both narrative and character speech. Here the narrative sections are marked by coordination and the speech by a strong presence of subordinate structures.

43 See the brief note of Horsfall (2008: 69 [on 2. 27] and 475 [on 2.669]).

44 Horsfall (2008: 475 [on Aen. 2. 669]).

45 Highet (1972: Appendix 1, 302). Highet compares his tally (treating the long narrative of Aeneas as one speech and ignoring the smaller speeches within it) with the other possibility (treating Aeneas' long narrative as though it were not direct speech and counting only the smaller speeches within that narrative). If we were to tally the lines of speech in the poem this way, we would find 3667 lines of speech (and the ratio of speech to narrative would be $37.1 \%)$. 
to present and to comprehend directly, as though in real time, than through indirect means. Furthermore, direct speech offers the audience the sense of 'being there'. And yet, to digress a little, Feeney has pointed out that whereas speech exchanges in Homer contribute to debates and negotiations of all kinds (whether inflammatory or healing or somewhere in between), Virgil has restricted conversational exchange. ${ }^{46}$ It is remarkable that more than one third of speeches made in the Aeneid do not receive a spoken reply. ${ }^{47}$ Perhaps Virgil has curtailed speech exchanges in the interest of compression and narrative pace, but the outcome is in fact more far-reaching: we do not see in Virgil the intimacy, the companionship, and the human warmth that we find in Homer.

Some of Virgil's similes appear to be presented in accordance with the Homeric model: see his simile at 2.471-475, for example, where Neoptolemus, appearing in the forecourt of the palace on the Trojan citadel, is compared to a snake that has returned to the light after its winter hibernation, fresh and gleaming, its energies renewed. ${ }^{48}$ The man who will slay Polites and then Priam is just such a creature, distinguished by his youth, his energy, and an instinctive desire to bring death—so like his father Achilles.

qualis ubi in lucem coluber mala gramina pastus,

frigida sub terra tumidum quem bruma tegebat, nunc, positis novus exuviis nitidusque iuventa, lubrica convolvit sublato pectore terga arduus ad solem, et linguis micat ore trisulcis.

He was like a snake which has fed on poisonous herbs and hidden all winter in the cold earth, but now it emerges into the light, casts its slough and is renewed. Glistening with youth it coils its slithering back and lifts its breast high to the sun with its triple tongue flickering from its mouth. transl. DAVID WEST

But whereas many of Homer's similes exhibit a single point of correspondence with the narrative from which they emerge, as did the simile from Il. 5.902-904, examined above, and whereas some of Homer's similes famously run beyond the narrative moment they are intended to illustrate, Virgil's similes not only exhibit careful correspondence with the narrative (indeed, a majority con-

\footnotetext{
46 See Feeney (1990: 180-181).

47 According to Feeney (1990: 180), of 333 speeches 135 do not receive a reply.

48 See Horsfall (2008: $363-364$ [on 2. 471-475]).
} 
tain more than one indicator of similarity), they also exhibit a careful correspondence across the narrative, with each other. ${ }^{49}$ Composition in writing has allowed Virgil the leisure to integrate his similes. The poet uses them not so much as explanatory devices to help the audience to recognize the scene he is describing (as does Homer); rather, his similes enhance the significance of the poem as a whole. ${ }^{50}$

On the other hand, some of Virgil's similes exhibit structural features that do not conform to those of his oral epic model. As Deborah Beck demonstrates elsewhere in this volume, Virgil often concludes his similes rather abruptly, failing to signal the resumption of the narrative (with non aliter or a similar phrase). Whereas Homer, with a listening audience in mind, took care to identify the hinge-point which closed the simile and returned the listener to the narrative, Virgil did not always adopt this 'oral' approach to the simile. ${ }^{51}$ In choosing occasionally not to include this signal Virgil gives notice to his audiences: they should not rely on the poet for every presentational cue; he is demanding their attention.

Furthermore, Virgil draws on a wider range of subjects for his similes than does Homer - and he uses his similes differently. He has expanded his stock of simile-material, occasionally abandoning the familiar rural themes of oral epic for a far narrower world, the social and political world of Rome: the world of the atrium-house or the villa and the family within it, the pleasure-grounds around Baiae and Cumae, or the crowd in the forum. ${ }^{52}$ In the first simile of the epic, at

49 For Homeric similes that run beyond the narrative to which they refer, see Il. 4.141-145; 12.299-306; 16.156-163 (and for commentary on these see Minchin [2001: 150-156]). On correspondences between simile and narrative and narrative and simile in Virgil's ('unilateral' and 'bilateral') similes, see West (1990): for striking examples (amongst many) see 4.437-439; 7.378-384; 11.486-497.

50 West (1990: 444). Virgil has also integrated his similes across the poem as a whole (I am grateful to Anne Rogerson for reminding me of this point): see Moulton (1974: 387-388), for a demonstration of Virgil's systematic use of simile-material to portray character (compare, e.g., the similes at Aen. 7.460-466 [on Turnus] and 8.18-25 [on Aeneas]); and see Schork (1986: 260-270), a demonstration of the 'cumulatively significant content' of the final simile of the epic (12.921-923).

On the poet's skill and care in assembling similes, see also Pöschl (1977: 195-196).

$5^{1} \quad$ See the important discussion by D. Beck in this volume; see also Williams (1973: on 12.749757, a simile describing Aeneas: and yet 'ille' at 758 must be Turnus); and see 9.339-341, a simile describing Nisus' slaughter of Rhamnes' men, which is followed immediately, without a resumptive phrase, by a narrative reference to Euryalus (9.342).

$5^{2}$ See Aen. $7 \cdot 378-384$ (in the atrium); $12.473-477$ (through the house and its porticoes); 
Aen. $1.148-153$, Neptune steps in to calm the storm at sea initiated by Juno to thwart the Trojan escape from Troy.
ac veluti magno in populo cum saepe coorta est
seditio saevitque animis ignobile vulgus, iamque faces et saxa volant, furor arma ministrant: tum, pietate gravem ac meritis si forte virum quem conspexere, silent arrectisque auribus astant; ille regit dictis animos et pectore mulcet:

As when disorder arises among the people of a great city and the common mob runs riot, wild passions find weapons for men's hands and torches and rocks start flying; at such a time if people chance to see a man who has some weight among them for his goodness and his services to the state, they fall silent, standing and listening with all their attention while his words command their passions and soothe their hearts ...

transl. DAVID WEST

The sea and the wind that stirs it are compared to a wild city crowd, out of control, hurling rocks and torches. Neptune himself is compared to a man of authority, a man who has held public office, who, with a few words, can calm the crowd and restore order. There is no doubt that the simile is vivid, but it does not work in the Homeric way. Here Virgil's simile draws on human behaviour in a specific environment to interpret a phenomenon of the natural world, one that is already familiar to the audience-the sudden abating of a storm. This simile is not required to clarify something that needs clarifying-rather, Virgil uses the simile to slow the pace of his narrative and to prolong the narrative moment (of course, these motives are not inconsistent with Homer's overall strategy), and, through this unexpected ploy, to retain his audience's attention. ${ }^{53}$ The Virgilian simile demonstrates high-level poetic skill; but it also indicates a poet who is prepared to challenge his audience.

12.473-477 (the Roman villa with its colonnades and atria and pools); 9.710-716 (the collapse of stone piers at Baiae).

53 This simile displays more than just the 'bilateral' features that West describes above; it illustrates a reversal of Homeric simile-practice. This is, however, not unusual as a general practice. The relationship between simile and the narrative from which it emerges may be mutually explanatory: Katz (1989: 495); Ortony (1979: 161-180).

On the question of similes as ornamentation, Horsfall (2006: xxxvi) remarks on the paucity of similes in Aen. 3, and suggests that this stretch of text had not been worked up 
Virgil's composition is less leisurely than Homer's. He has used less repetition at the level of formula and type-scene, and minimal repetition at the narrative level of, say, the message.$^{54} \mathrm{He}$ does not support a listening audience in the same conspicuous way that Homer does. The reason for this lies in the fact that neither his initial listening audience nor any subsequent audience is required to give the poet sustained attention over time. Unlike the audience at an eightor nine-hour performance of oral song, ${ }^{55}$ a Roman guest at a recitatio will hear relatively short passages specifically selected by the poet for their appropriateness to the occasion and to the audience. And, unlike Homer's audiences, for whom the experience of song is ephemeral, the Roman guest-literate, and with leisure time-knows that he will be able to borrow or a purchase a copy of the work that he has just heard - which he can then read for himself, at his own pace, and in his own time. ${ }^{56}$ As Pliny says (Letters 9.27), liber tamen ... manet manebit legeturque semper.

\section{The Opportunities Offered by Literacy, and Its Challenges}

How did Virgil use the advantages that literacy offered him-specifically, the advantage of time for the poet to compose at leisure and for the audience to read at leisure; the knowledge that any reading that he gave of his work would be on his own terms; and the more distant prospect of having a written text in circulation? As we have seen, Virgil in his Aeneid had disregarded the repetitions of oral epic: he recognized that in his world these features were unnecessary. On the other hand, given that a reader can at any moment lay a book aside, Virgil worked to engage his audience, at every level; and he insisted on their attention. ${ }^{57}$ An interesting token of Virgil's claim on their attention (at a lower presentational level) are his 'golden lines', in which the poet distributes two adjectives and two nouns around a centrally occurring

and elaborated with imagery and metaphor: Virgil does not regard his similes as essential explanatory devices, as does Homer.

54 Insistent word-for-word repetition is minimal, for example, in the message that Jupiter gives to Mercury and that Mercury passes on to Aeneas: see Aen. 4.227-237 and 265-276although, to be sure, the message itself is conveyed.

55 And unlike the audience today that listens to a scholar reading a densely argued paper.

56 See on this Parker (2009: 208): '... if you wanted to enjoy the same poem a second time, you had to resort to the written text'; and Martial 2.6.1-9; 10.20.

57 On involving one's audience, see Minchin (2001: 213-216). 
verb. ${ }^{58}$ We can envisage that both listener and reader learnt to recognize and to adapt to the counter-intuitive word order of such lines - and were engaged by this small challenge. But the poet devised challenges at a higher level also. Since Virgil's epic constantly refers to and plays against the Homeric epics, in structure, in content, and in aspects of presentation, his audiences are invited to process both the sameness and the difference of the Aeneid vis-à-vis the Iliad and the Odyssey. ${ }^{59}$ I refer here to the burden-and the pleasures—of intertextuality.

Virgil's cross-references to the Homeric poems are rarely straightforward one-for-one correspondences: if we look to his character models, for example, we discover that the Trojans of the Iliad have become the Achaians of the Aeneid; Aeneas himself has become both a new Odysseus and a new Achilles; Turnus is a new Menelaus, a new Paris, and ultimately a new Hector. ${ }^{60}$ These references to those other Troy-stories are not mere digressions, or ornaments; the audience is required to make these connections in order to follow where the poet leads. ${ }^{61}$ As David Lodge's Robyn Penrose says, 'Difficulty generates meaning. It makes the reader work harder' ${ }^{62}$

Virgil paints an infinitely more complicated picture than does Homer of heroic identity and heroic adventure-and of history. To the extent that the Aeneid gives an account of the founding of Rome, it is 'historical'. And yet this work is also allegorical, in that the political situation in contemporary Rome is recreated in the trials that Aeneas faced in founding his city. ${ }^{63}$ In its depiction of Roman virtues and Roman values the poem is distinctly moralistic. And it is aetiological, tracing the 'origins' of many contemporary Roman institutions. If Virgil's readers are to appreciate the epic in its entirety and reflect on its layers of meaning, relating past to present and present to past, ${ }^{64}$

58 The careful ordering of the so-called 'golden line', of which there are several examples in the Aeneid (e.g. at 4.139, aurea purpuream subnectit fibula vestem; or, at 8.596, quadripedante putrem sonitu quatit ungula campum), is a phenomenon not apparently remarked upon in ancient criticism. On the golden line in Virgil, see Scully (2006: 405). As listeners or readers process the line, one of their four (or, according to Miller, seven) available 'chunks' of attention is taken up by this single phenomenon.

59 I am assuming educated readers here: readers who know their Homer thoroughly.

$60 \quad$ On Turnus (in his own eyes) as Menelaus (Aen. 9.136-139) and as Achilles (9.741-742). On Turnus as Paris (11.213-219).

61 For discussion of some of these points from another perspective, see James O'Maley's chapter in this volume.

62 Lodge (1988: 240).

63 See Johnson (1976: 16-22).

64 On these meanings see, e.g., Lyne (1987:1-3). 
they must read attentively and allow time for the poem to play out in their thoughts.

\section{Medium, Mode, and Strategies of Presentation}

As we consider the relationship between poet, text and audience I have asked whether or not the medium and the mode matter. Of course they do. As Chafe's work has shown, a different medium and a different mode require, or allow, different strategies of presentation.

What I have argued is that the oral traditional poet - the singer - is equipped with strategies for composition that complement neatly the processing needs of the audience who hears him, in the context of sustained performance; and that the strategies of oral epic song that we have observed are the product of this complementarity of needs. On the other hand, we find that a poet in the Roman context who composed in writing for imagined recipients (listeners in the first instance and, subsequently, readers) felt little pressure to adapt his written text to his first audience. This audience was literate and educated: they were experienced in the genre. Their 'cognitive ceiling', qualitatively, was at least compatible with his own. Virgil's compositional practices indicate that he recognized the value of certain strategies that we identify today as critical for a listening audience in an oral context — the 'adding on' habit and direct speech; but Virgil used them for his own poetic purposes. On the other hand, we have found that those consistent patterns of repetition that we associate with oral epic are barely present. This indicates that the poet is confident that, at a recitatio, for example, he can catch the attention of his listening audience, by virtue of a semi-traditional, clear, narrative style, and hold it, by virtue of its special aural qualities, on the one hand, and the gravity and grandeur of his hero's mission - thanks to their education, their cultural knowledge, and their experience in listening to literary works.

But Virgil did not intend his work to be performed in 'bits and pieces' for sympathetic listeners at recitationes. ${ }^{65}$ He seized upon the advantages of composition in writing - and the advantages, for his readers, of a written text. He used the years available to him as he worked on his epic to reflect the chaotic period through which he had lived, incorporating more complexity, more ambiguity, into his epic than an oral poet like Homer ever could. ${ }^{66} \mathrm{He}$

65 Parker (2009: 208).

66 On this see Griffin (1986: 102-106). 
reworked the tradition that he inherited to produce an absorbing multi-layered Roman epic - history and myth, allegory and allusion. If we evaluate the poem as a whole, therefore, in terms of structure and meaning as well as presentation, we see that Virgil has effectively produced a text that rewards attentive reading. This is a text destined for educated readers, for those who have the means to purchase a copy of his work and the leisure to engage with it.

The medium therefore matters, but the extent to which it matters is related not only to the 'cognitive ceiling' of the poet but also to the mode-and the occasion - of reception, and the 'cognitive ceiling' of the audience. Virgil respected and acknowledged the tradition he inherited. Like Homer's bards, he was prepared to perform for an audience of listeners; but it was because of the enabling power of writing to transmit works of literature across time that he put his efforts into negotiating a relationship that the oral epic tradition had never envisaged, a relationship with an audience of educated and experienced readers.

\section{Bibliography}

Bakker, E. 1988. Linguistics and Formulas in Homer: Scalarity and the Description of the Particle $\pi \varepsilon p$. Amsterdam:John Benjamins.

Bakker, E. 1993. 'Topics, Boundaries, and the Structure of Discourse: An Investigation of the Particle $\delta \varepsilon \dot{\prime}$. Studies in Language 17: 275-311.

Bakker, E. 1997. Poetry in Speech: Orality and Homeric Discourse. Ithaca and London: Cornell University Press.

Biber, D. 1988. Variation across Speech and Writing. Cambridge: Cambridge University Press.

Chafe, W. 1982. 'Integration and Involvement in Speaking, Writing, and Oral Literature' in D. Tannen, ed. Spoken and Written Language: Exploring Orality and Literacy. Advances in Discourse Processes 9, 35-53. Norwood, N.J.: Ablex.

Clausen, W. 2002. Virgil's Aeneid: Decorum, Allusion, and Ideology. Munich and Leipzig: K.G. Saur.

Cowan, N. 2001. 'The Magical Number 4 in Short-Term Memory: A Reconsideration of Mental Storage Capacity'. Behavioral and Brain Sciences 24: 87-114.

de Waal, E. 2011. The Hare with Amber Eyes: A Hidden Inheritance. London: Vintage Books.

Feeney, D.C. 1990. 'The Taciturnity of Aeneas' in S.J. Harrison ed., Oxford Readings in Vergil's Aeneid, 167-190. Oxford: Oxford University Press.

Foley, J.M. 1991. Immanent Art: From Structure to Meaning in Traditional Oral Epic. Bloomington: Indiana University Press. 
Goffman, E. 1981. Forms of Talk. Philadelphia: University of Pennsylvania Press.

Griffin, J. 1986. Homer. Oxford: Oxford University Press.

Gulich, E. and M. Quasthoff. 1986. 'Storytelling in Conversation: Cognitive and Interactive Aspects'. Poetics 15: 217-241.

Haslam, M. 1997. 'Apollonius Rhodius and the Transmission of the Text' in I. Morris and B. Powell eds. A New Companion to Homer, 55-122. Leiden: Brill.

Highet, G. 1972. The Speeches in Vergil's Aeneid. Princeton, N.J.: Princeton University Press.

Hildyard, A. and D. Olson. 1982. 'On the Comprehension and Memory of Oral vs. Written

Discourse' in D. Tannen, ed. Spoken and Written Language: Exploring Orality and Literacy. Advances in Discourse Processes 9, 19-33. Norwood, N.J.: Ablex.

Horsfall, N. 2006. Virgil, Aeneid 3: A Commentary. Leiden: Brill.

Horsfall, N. 2008. Virgil, Aeneid 2: A Commentary. Leiden: Brill.

Johnson, W.R. 1976. Darkness Visible: A Study of Vergil's Aeneid. Berkeley: University of California Press.

Katz, A. 1989. 'On Choosing the Vehicles of Metaphors: Referential Concreteness, Semantic Distances, and Individual Differences'. Journal of Memory and Language 28: 486-499.

Kirk, G.S. 1985. The Iliad: A Commentary, vol. 1. Cambridge: Cambridge University Press.

Knauer, G.N. 1990. 'Vergil's Aeneid and Homer' in S.J. Harrison, ed. Oxford Readings in Vergil's Aeneid, 390-412. Oxford: Oxford University Press.

Labov, W. 1972. Language in the Inner City: Studies in the Black English Vernacular. Philadelphia: University of Pennsylvania Press.

Lodge, D. 1988. Nice Work: A Novel. London: Secker and Warburg.

Lyne, R.O.A.M. 1987. Further Voices in Vergil's Aeneid. Oxford: Oxford University Press.

Miller, G. 1956. 'The Magical Number Seven, Plus or Minus Two: Some Limits on Our Capacity for Processing Information'. Psychological Review 63: 81-97.

Miller, J. and R. Weinert, eds. 1998. Spontaneous Spoken Language: Syntax and Discourse. Oxford: Clarendon Press.

Minchin, E. 2001. Homer and the Resources of Memory: Some Applications of Cognitive Theory to the Iliad and the Odyssey. Oxford: Oxford University Press.

Moskalew, W. 1982. Formular Language and Poetic Design in the Aeneid. Leiden: Brill.

Moulton, C. 1974. 'Similes in the Iliad'. Hermes 102: 381-397.

Neisser, U. 1982. 'Literacy and Memory' in U. Neisser, ed. Memory Observed:Remembering in Natural Contexts. San Francisco: W.H. Freeman.

Notopoulos, J. 1949. 'Parataxis in Homer'. Transactions of the American Philological Association 80: 1-23.

Notopoulos, J. 1951. 'Continuity and Interconnexion in Homeric Oral Composition'. Transactions of the American Philological Association 82: 81-101. 
Ortony, A. 1979. 'Beyond Literal Similarity', Psychological Review 86: 161-180.

Parker, H. 2009. 'Books and Reading Latin Poetry' in W. Johnson and H. Parker, eds. Ancient Literacies: The Culture of Reading in Greece and Rome, 186-229. Oxford: Oxford University Press.

Parry, A. ed. 1987 [1971]. The Making of Homeric Verse: The Collected Papers of Milman Parry. Oxford: Oxford University Press.

Pöschl, V. 1977. Die Dichtkunst Virgils: Bild und Symbol in der Äneis. Berlin: de Gruyter.

Ready, J. 2011. Character, Narrator, and Simile in the Iliad. New York: Cambridge University Press.

Ready, J. 2012. 'Comparative Perspectives on the Composition of the Homeric Simile' in E. Minchin ed. Orality, Literacy and Performance in the Ancient World, 55-87. Leiden: Brill.

Redfield, J. 1975. Nature and Culture in the Iliad: The Tragedy of Hektor. Chicago: University of Chicago Press.

Russo, J. 1999. 'Sicilian Folktales, Cognitive Psychology, and Oral Theory' in T. Falkner, N. Felson and D. Konstan, eds. Contextualizing Classics: Ideology, Performance, Dialogue, 151-171. Lanham: Rowman and Littlefield.

Schork, R. 1986. 'The Final Simile in the Aeneid: Roman and Rutulian Ramparts'. American Journal of Philology 107: 260-270.

Scodel, R. 2002. Listening to Homer: Tradition, Narrative, and Audience. Ann Arbor: The University of Michigan Press.

Scribner, S. and M. Cole. 1981. The Psychology of Literacy. Cambridge, Mass.: Harvard University Press.

Scully, S. 1990. Homer and the Sacred City. Ithaca and London: Cornell University Press.

Scully, S. 2006. 'Homeric Epithets and Translation'. International Journal of the Classical Tradition 13: 404-415.

Tannen, D. 1982a. 'Oral and Literate Strategies in Spoken and Written Narratives'. Language 58: 1-21.

Tannen D. 1982b. 'The Oral/Literate Continuum in Discourse' in D. Tannen, ed. Spoken and Written Language: Exploring Orality and Literacy. Advances in Discourse Processes 9, 1-16. Norwood, N.J.: Ablex.

Tannen, D. 1988. 'The Commingling of Orality and Literacy in Giving a Paper at a Scholarly Conference'. American Speech 63: 34-43.

Tarrant, R. 2012. Virgil, Aeneid Book XII. Cambridge: Cambridge University Press.

Taplin, O. 1995. Homeric Soundings: The Shaping of the Iliad. Oxford: Clarendon Paperbacks, Oxford University Press.

Vivante, P. 1982. The Epithets in Homer: A Study in Poetic Values. New Haven: Yale University Press.

West, D.A. 1990. 'Multiple-Correspondence Similes in the Aeneid' in S.J. Harrison, ed. Oxford Readings in Vergil's Aeneid, 429-444. Oxford: Oxford University Press. 
West, D.A. 1991. Virgil, The Aeneid. London: Penguin Books.

Williams, R.D. ed. 1973. Virgil, Aeneid VII-XII. Bristol: Bristol Classical Press. 